Article

\title{
Static balance ability of persons with visual impairment on firm and foam surfaces
}

Triloki Prasad $^{1 *}$, Subhankar Ghosh $^{2}$ and Asis Goswami ${ }^{1}$

Received: $20^{\text {th }}$ November 2018; Accepted: $3^{\text {rd }}$ February 2020; Published: $8^{\text {th }}$ May 2020

Abstract: The Balance Error Scoring System (BESS) is an easily administered test of short duration static balance. In daily activities including sports, people with low vision (partially sighted) or partial blindness and visual impairment face difficulty while balancing their body in static positions. The purpose of this study is to test balance and stability of people with low vision or partially sightedness (PS) and full blindness (FB) using BESS test. The BESS was used to measure the error in the range from o for "excellent balance" and 10 for "very poor balance". A total of 106 volunteers participated in the study that included 43 PS (mean age $=17.5 \mathrm{y}, \mathrm{SD}=$ $3.2 \mathrm{y}$ ) and $63 \mathrm{FB}$ (mean age $=2 \mathrm{yy}, \mathrm{SD}=3.4 \mathrm{y}$ ) volunteers. The test for the BESS was taken for Non-Dominant Leg (NDL) and Dominant Leg (DL). Descriptive statistics and non-parametric tests were carried out. The study revealed that all the combinations of correlation between Firm Surface (FS) and Foam Surface (FOS) were statistically significant at $\mathrm{p}<.05$. Test of age, height, and weight of the PS and FB group indicated significant differences between the groups in these variables. Surface firmness is less effective in evaluating balance for persons with visual impairments.

Keywords: Balance Error Scoring System; Leg Dominance; Effect of stance

\section{Introduction}

Three systems that regulate upright standing posture in human are visual, vestibular and somatosensory (Aydoğ, Aydoğ, Cakci, \& Doral, 2006). It was suggested that optimal postural stability in a variety of situations requires information from all the three sensory systems (Horak, Diener \& Nashner, 1989). Vision provides continuous information about the location and the position of the body in the environment that helps in alignment of the body parts as required. Previous studies have indicated that loss of information from eyes may cause persons with visual impairment to suffer from sudden fall, injuries and complete loss of balance (Horak, Diener, \& Nashner, 1989; Nashner, Black, \& Wall, 1982). It is known that among persons with visual impairment parts of the visual cortex are activated by other types of sensory stimulations in a cross-modal manner (Cohen et al., 1997; Theoret, Merabet, \& Pascual, 2004). It means that some of the visual cortex would respond to sensory input from other remaining senses. However, this type of cross-modal plasticity would not be helpful in balancing functions. An individual needs the ability to control the relationship between the centre of mass (COM) and the base of support to maintain postural stability against disturbance (Winter, 2009). Absence of visual information affects the development of good postural habits (Alotaibi, Alghadir, Iqbal, \& Anwer, 2016) and leads to many successive postural deviations in both static and dynamic situations. These lead to the incorrect distribution of muscular force throughout the body which precipitates postural 
imbalance. Successful performance of static balance indicates that all force and torque acting on the body are in balance and the person's COM is within their control. Persons with visual impairment mainly rely on somatosensory and vestibular information to maintain postural stability and also adjust body positions in space to compensate for restrictions of vision (Anand, Buckley, Scally, \& Elliott, 2003; Horvat, Ray, Ramsey, Miszko, Keeney \& Blasch, 2003). Few studies (Bell, Guskiewicz, Clark, \& Padua,2011; Guskiewicz, \& Perrin, 1996, Hassan, 1989, Shumway-Cook, \& Horak, 1986, Shumway-Cook \& Woollacott, 2007) suggest that vestibular information is not necessary for postural orientation during quiet stance when other sensory information is available. Rather, stability gets reduced in the absence of vision (Friedrich et al., 2008).

Various attempts were made to assess the static balance ability of persons who had suffered concussion (Broglio, Zhu, Sopiarz, \& Park, 2009; Collins et al, 1999; Jansen, Larsen, \& Olesan, 1982; McCrea, Kelly, Kluge, Ackley, \& Randolph, 1997; Shumway-Cook, \& Horak, 1986; Sugano \& Takeya, 1970). Many of them were dependent on shophisticated instruments and trained manpower. The Balance Error Scoring System (BESS) was developed as a method of evaluating postural stability without the use of complex or expensive equipment (Fregly, 1974; Guskiewicz, 2001). The purpose of the study was to explore the stability and balance characteristics of persons with visual impairment through the use of Balance Error Scoring system.

\section{Materials and Methods}

\section{Subjects}

Volunteers $(n=106)$ were taken from a local Blind School in the age group of 13-27 years. The volunteers were classified in two groups following the classification system described in International Classification of Diseases, Tenth Revision (ICD-10, WHO, 2016). Category H54 of ICD-10 describes the classification of Visual Impairment including blindness (binocular or monocular). Volunteers $(n=43)$ belonged to categories $2 \& 3$ (Partially Sighted; PS) of $\mathrm{H}_{54}$ and 63 were in categories 4 \& 5 (Full Blind; FB). The volunteers had no known impairment in the other sensory or musculoskeletal system. The mean age of the PS group volunteers was $17.5 \mathrm{y}(\mathrm{SD}=3.2 \mathrm{y})$ and of the $\mathrm{FB}$ group was $20.0 \mathrm{y}(\mathrm{SD}=3.4 \mathrm{y})$. The body height and weight of the volunteers were measured using an anthropometer and an Omron digital weight scale following the methods described in ISAK Manual (Stewart et al, 2011). Three trials were attempted while measuring these values and the average of the three trials was accepted. The mean height of the volunteers in the PS group was $154.6 \mathrm{~cm}(\mathrm{SD}=7.1 \mathrm{~cm})$ and mean weight was $51.1 \mathrm{~kg}(\mathrm{SD}=6.9 \mathrm{~kg})$ and the corresponding values for $\mathrm{FB}$ group were height as $158.3 \mathrm{~cm}(\mathrm{SD}=6.9 \mathrm{~cm})$ and weight as $51.1 \mathrm{~kg}(\mathrm{SD}=9.0 \mathrm{~kg})$. All volunteers gave written informed consent prior to participation. This study was approved by the Institutional Ethical Review Board at Ramakrishna Mission Vivekananda Educational and Research Institute, Coimbatore, India. Each volunteer was asked to inform which foot they would use for the football kick and the Dominant Leg (DL) was determined accordingly. In this experiment, six trials for DL and six trials for Non-Dominant Leg (NDL) were taken.

\section{Experimental Design and Procedure}

During the experiment, the volunteers were blindfolded by wearing a non-transparent cloth that completely occluded their central and peripheral vision. This was done to provide similar visual condition to the volunteers groups. The volunteers were instructed to adopt three different erect test positions (stance) during the test and in barefoot condition. Tested positions were: a) feet touching side-by-side (double leg stance), b) a single leg stance and c) a heel-to-toe stance (tandem stance). In each stance the hands were kept on the side of the hip. Every stance was carried out on two different types of surface. The first surface was 
floor of the building that had high rigidity (Figure 1). The second type was a piece of thick foam pad containing micro air pockets of $50 \mathrm{~cm} \times 41 \mathrm{~cm} \times 6 \mathrm{~cm}$ dimension (Figure 2). The volunteers were told to hold each stance for 20 seconds continuously without changing the stance and any change in the stance would be considered as error. They were told about the possible errors as given in Table 1. In the event of coming out of the stance before the end of 20 seconds the volunteers returned to the position as quickly as possible. The scoring was determined by the recording of errors following the method described by Riemann and colleagues (Riemann, Guskiewicz, \& Shields, 1999) and is given in Table 1. Each deviation from the required stance was taken as one error. The highest possible score for one trial was 10 error points. If a subject could not maintain one of the positions for at least 5 seconds during a trial, the highest error score of 10 was assigned to the volunteer for that trial. Participants performed three trials in each condition of the NDL and DL on both surfaces and data were recorded. The data with double leg stance was taken for six times since in this case leg dominance is not possible in this stance. One of the test items 'Opening the eyes' was not valid for the present study, therefore no such situation was recorded.

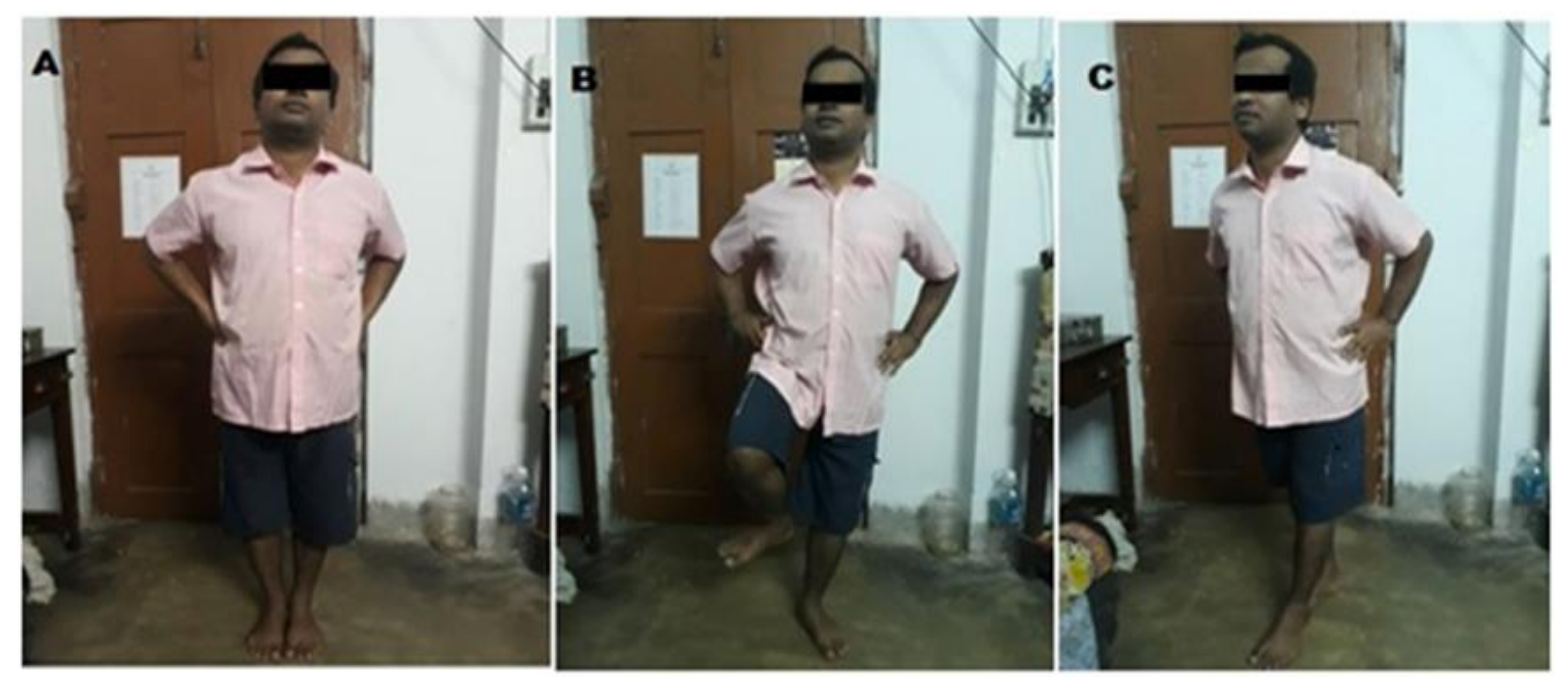

Figure 1. A. Double Leg stance; B. Single Leg stance; C. Tandem stance on the firm (hard) surface in both Non-Dominant Leg (NDL) and Dominant Leg (DL).

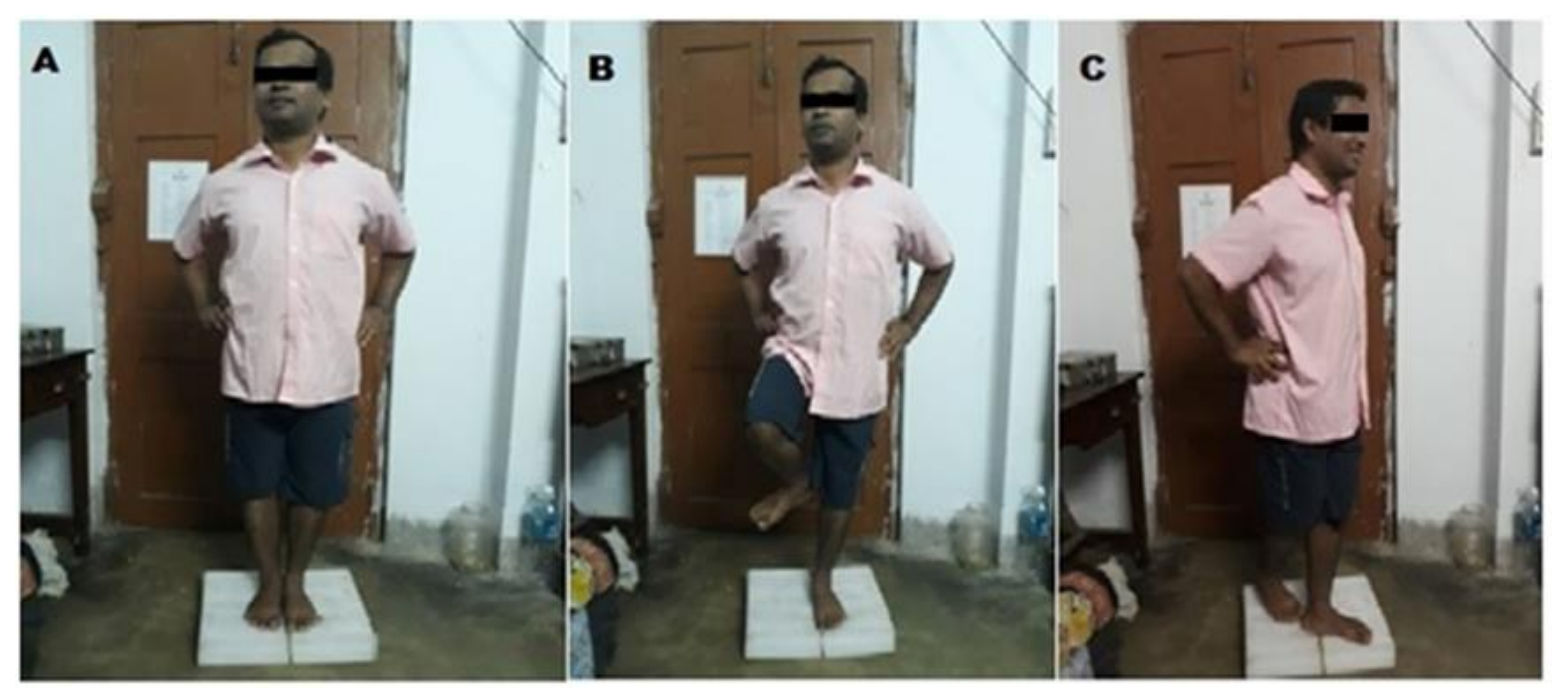

Figure 2. A. Double Leg stance; B. Single Leg stance; C. Tandem stance on the foam (soft) surface in both Non-Dominant Leg (NDL) and Dominant Leg (DL)

\section{Statistical Calculation}

At first, the data were treated through the Anderson-Darling test to determine whether they are following a normal distribution. Anderson-Darling test has been indicated as a best 
choice for small sample data (Razali, \& Wah, 2011). None of the variables were found to fall in normal distribution fitting. Therefore, non-parametric tests were done for the statistical procedures. Kendall's tau coefficient was calculated to study the relationship in relevant variables (Table 2). Wilcoxon-Mann-Whitney Test was carried out to find out the significance level of differences between the variables (Table 2). Statistical significance was set at $\mathrm{p}<0.05$. Further, $\mathrm{R}$ studio and Gnumeric software were used for the statistical calculations.

Table 1. List of items in Balance Error Scoring System*

\begin{tabular}{ll}
\hline $\begin{array}{l}\text { Serial } \\
\text { Number }\end{array}$ & Errors \\
\hline 1 & Lifting hands off the iliac crests \\
2 & Opening the eyes \\
3 & $\begin{array}{l}\text { Stepping, stumbling or falling } \\
\text { Moving the hip into more than } 30^{\circ} \text { of flexion or } \\
\text { abduction }\end{array}$ \\
5 & $\begin{array}{l}\text { Lifting the forefoot or heel } \\
\text { Remaining out of the testing position for more } \\
6\end{array}$ \\
\end{tabular}

Table 2. Comparison sets and the categories for the Wilcoxon-Mann-Whitney Test and Kendall's Tau.

\begin{tabular}{|c|c|c|c|c|c|c|}
\hline Category & Compari & on sets & & & & \\
\hline $\begin{array}{l}\text { Stance } \\
\text { effect }\end{array}$ & $\begin{array}{l}\text { NDL } \\
\text { FS SLS } \\
\text { vs TS }\end{array}$ & $\begin{array}{l}\text { NDL } \\
\text { FOS } \\
\text { SLS vs } \\
\text { TS }\end{array}$ & $\begin{array}{l}\text { NDL TOTAL of } \\
\text { Surface SLS vs TS } \\
\text { (Two surfaces } \\
\text { added) }\end{array}$ & $\begin{array}{l}\text { DL FS } \\
\text { SLS vs } \\
\text { TS }\end{array}$ & $\begin{array}{l}\text { DL FOS } \\
\text { SLS vs } \\
\text { TS }\end{array}$ & $\begin{array}{l}\text { DL TOTAL of } \\
\text { Surface SLS vs } \\
\text { TS (Two } \\
\text { surfaces added) }\end{array}$ \\
\hline $\begin{array}{l}\text { Leg } \\
\text { dominance }\end{array}$ & $\begin{array}{l}\text { FS SLS } \\
\text { NDL vs } \\
\text { DL }\end{array}$ & $\begin{array}{l}\text { FS TS } \\
\text { NDL vs } \\
\text { DL }\end{array}$ & $\begin{array}{l}\text { FS TOTAL OF } \\
\text { STANCE NDL vs } \\
\text { DL (Two stances } \\
\text { added) }\end{array}$ & $\begin{array}{l}\text { FOS } \\
\text { SLS } \\
\text { NDL vs } \\
\text { DL }\end{array}$ & $\begin{array}{l}\text { FOS TS } \\
\text { NDL vs } \\
\text { DL }\end{array}$ & $\begin{array}{l}\text { FOS TOTAL } \\
\text { OF STANCE } \\
\text { NDL vs DL } \\
\text { (Two stances } \\
\text { added) }\end{array}$ \\
\hline $\begin{array}{l}\text { Surface } \\
\text { effect }\end{array}$ & $\begin{array}{l}\text { NDL } \\
\text { SLS FS } \\
\text { vs FOS }\end{array}$ & $\begin{array}{l}\text { NDL } \\
\text { TS FS } \\
\text { vs FOS }\end{array}$ & $\begin{array}{l}\text { NDL TOTAL OF } \\
\text { STANCE FS vs } \\
\text { FOS (Two stances } \\
\text { added) }\end{array}$ & $\begin{array}{l}\text { DL SLS } \\
\text { FS vs } \\
\text { FOS }\end{array}$ & $\begin{array}{l}\text { DL TS } \\
\text { FS vs } \\
\text { FOS }\end{array}$ & $\begin{array}{l}\text { DL TOTAL OF } \\
\text { STANCE FS vs } \\
\text { FOS (Two } \\
\text { stances added) }\end{array}$ \\
\hline $\begin{array}{l}\text { Nature of } \\
\text { Blindness }\end{array}$ & $\begin{array}{l}\text { FS } \\
\text { SLS FB } \\
\text { vs PS }\end{array}$ & $\begin{array}{l}\text { FS } \\
\text { TS FB } \\
\text { vs PS }\end{array}$ & $\begin{array}{l}\text { FST FB vs PB (Two } \\
\text { stances added) }\end{array}$ & $\begin{array}{l}\text { FOS } \\
\text { SLS FB } \\
\text { vs PS }\end{array}$ & $\begin{array}{l}\text { FOS } \\
\text { TS FB } \\
\text { vs PS }\end{array}$ & $\begin{array}{l}\text { FOST FB vs } \\
\text { PS(Two stances } \\
\text { added) }\end{array}$ \\
\hline
\end{tabular}

NDL= Non dominant leg; DL=Dominant leg; FS= Firm surface; FOS foam surface; TS= Tandem stance; SLS= Single Leg Stance; FST= Firm surface Total; FOST = Foam surface total; FB= Full Blind; PS=Partially Sighted.

\section{Results}

From the significance test of age, height, and weight of the PS and FB group there were statistically significant difference between the groups in these variables. In double leg stance, most of the volunteers did no error barring two volunteers, each, in the PS and FB group. The BESS errors in case of FB group on the firm surface (mean $=0.2$, median $=0.0, \mathrm{SD}=$ 1.3) and on foam surface (mean $=0.3$, median $=0.0, S D=1.9$ ). In PS group the BESS error values on the firm surface (mean $=0.07$, median $=0.0, \mathrm{SD}=0.3$ ) and on the foam surface (mean $=0.02$, median $=0.0, \mathrm{SD}=0.2$ ). No surface related or state of blindness related statistically significant difference was found when these data were placed through the significance test. 
The right foot was the dominant leg of all volunteers. The BESS score in the nondominant leg and dominant leg support for PS and FB groups were shown in table 3. The results from the data indicate that tandem stance (TS) leads to fewer number of errors irrespective of leg dominance and surface condition, but with a large variance within the values. Larger variance leads to the possibility of the presence of outlier data in TS condition and the difference became non-significant. This is evident when the values of TS or SLS (values in FS and FOS added) were taken in the box plot (Figure 3).

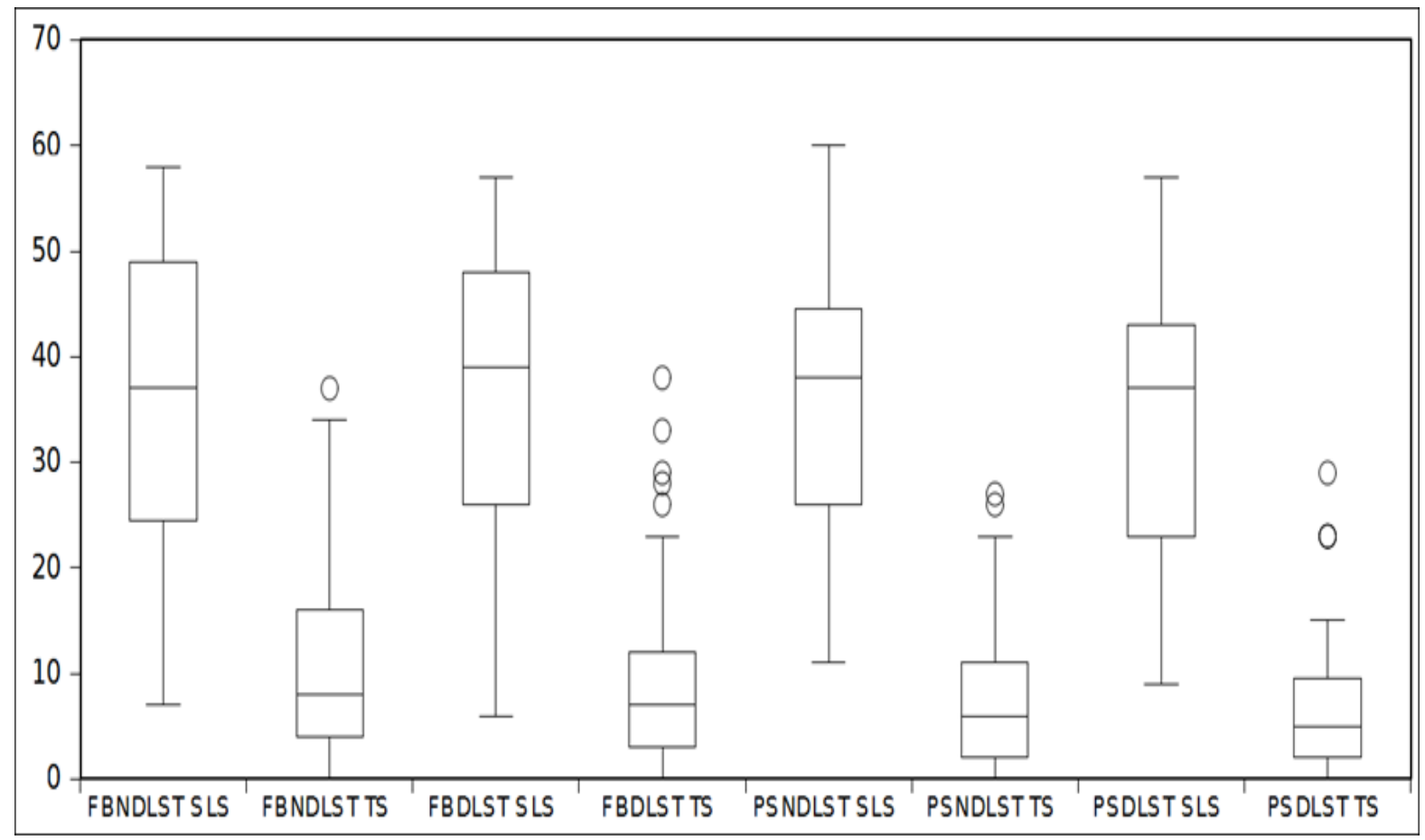

$\mathrm{FB}=$ Full Blind

$\mathrm{TS}=$ Tandem Stance
PS=Partially Sighted

SLS=Single Leg

Stance

Figure 3: Box Plot of the sum of errors in Firm Surface (FS) and Foam Surface (FOS) for different dominance and stance conditions

Four categories of comparison were evaluated through tests of significance and relationship between the sets of variables. They are given in Table 3. These sets were carried out for FB and PS groups except for the comparison of effect of nature of blindness.

Table 3: BESS score in Non-Dominant and Dominant Leg support

\begin{tabular}{|c|c|c|c|c|c|c|c|c|c|}
\hline \multirow[b]{3}{*}{ Group } & \multirow[b]{3}{*}{ Statistics } & \multicolumn{4}{|c|}{ Non-Dominant Leg support } & \multicolumn{4}{|c|}{ Dominant Leg support } \\
\hline & & \multicolumn{2}{|c|}{ Firm Surface } & \multicolumn{2}{|c|}{ Foam Surface } & \multicolumn{2}{|c|}{ Firm Surface } & \multicolumn{2}{|c|}{ Foam Surface } \\
\hline & & $\begin{array}{l}\text { Single } \\
\text { Leg } \\
\text { Stance }\end{array}$ & $\begin{array}{l}\text { Tandem } \\
\text { Stance }\end{array}$ & $\begin{array}{l}\text { Single } \\
\text { Leg } \\
\text { Stance } \\
\end{array}$ & $\begin{array}{l}\text { Tandem } \\
\text { Stance }\end{array}$ & $\begin{array}{l}\text { Single } \\
\text { Leg } \\
\text { Stance }\end{array}$ & $\begin{array}{l}\text { Tandem } \\
\text { Stance }\end{array}$ & $\begin{array}{l}\text { Single } \\
\text { Leg } \\
\text { Stance } \\
\end{array}$ & $\begin{array}{l}\text { Tandem } \\
\text { Stance }\end{array}$ \\
\hline \multirow{4}{*}{ FB } & mean & 15.2 & 4.4 & 20.8 & 6.7 & 15.9 & 4.1 & 20.9 & 5.4 \\
\hline & med & 15.0 & 3.0 & 22.0 & 4.0 & 18.0 & 3.0 & 23.0 & 3.0 \\
\hline & SD & 8.4 & 4.3 & 7.5 & 6.2 & 8.2 & 4.1 & 6.7 & 5.3 \\
\hline & mean & 15.6 & 3.2 & 20.0 & 4.6 & 14.5 & 3.1 & 19.0 & 3.9 \\
\hline \multirow{2}{*}{ PS } & med & 15.0 & 2.0 & 23.0 & 3.0 & 15.0 & 2.0 & 22.0 & 2.0 \\
\hline & $\mathrm{SD}$ & 6.5 & 3.3 & 6.7 & 4.3 & 7.2 & 3.6 & 6.8 & 4.3 \\
\hline
\end{tabular}

med = Median, SD = Standard Deviation, FB = Full blind, PS = Partially Sighted 


\section{Comparison of the Effect of Stance}

When stance was compared keeping the same surface and dominance, the difference in medians in case of both FB and PS were found statistically significant in all comparisons. From the correlational analyses all the combinations of correlation between SLS and TS were statistically significant. The highest correlation value was $r=0.5$.

\section{Effect of leg Dominance}

In contrast to the above two comparisons of the effect of stance between FB and PS, leg dominance did not elicit any statistically significant difference in medians. However, from the correlational analyses, all the combinations of correlation between NDL and DL were statistically significant. The highest correlation value was $r=0.73$.

\section{Comparison of the effect of Surface on Balance Ability}

Comparisons were made between the surfaces keeping the same stance and dominance. The difference in medians in case of FB was statistically significant in all comparisons except in case of Tandem stance with the dominant limb. For PS group TS with non-dominant and dominant both cases were not statistically significant although the values for FOS were higher in all the cases. From the correlational analyses all the combinations of correlation between FS and FOS were statistically significant. The highest correlation value was $\mathrm{r}=0.66$.

\section{Discussion}

Posture control in a human being requires maintaining the body position in space and the relationship of segments. The well-controlled human body will have the stability that would be determined by the position of the axis of the COM in relation to the base of support (Shumway-Cook, \& Woollacott, 2007). It is natural that a double leg stance would provide better stability compared to single leg stance. Little error during double leg stance, found in the present study, supports this view. Since it is expected that both the limbs will take the body weight equally, the question of the dominant limb or non-dominant limb does not arise in case of double leg stance. A higher number of errors in a single leg stance indicates lower balance ability of persons with visual impairments (Docherty, Valovich McLeod, \& Shultz, 2006)

It is important to note that the FB volunteers were taller than PS volunteers in the present study. There could be an effect of body height in the number of errors since taller persons may show greater postural sway. Further study would be required to provide a firm opinion on this aspect.

\section{Effect of Stance}

In case of tandem stance, although a type of double leg stance, the size of the base of support is less broad than a simple double leg stance (feet placed side by side) (Hile, Brach, Perera, Wert, Van Swearingen, \& Studenski, 2012). In double leg stance, the body weight is generally carried by both the foot equally while in tandem stance the foot in the rear position is anticipated to bear the major part of the body weight (Jonsson, Seiger, \& Hirschfeld, 2005). This tandem position is expected to evaluate the lateral balance ability of a person, because the base in the stance is spread in an anteroposterior direction. Foot dominance could be an issue in determining the balance in this posture. Significantly lower error, in the present study, was found in TS as compared to SLS indicating that TS provides better balance than SLS. Correlation values between SLS and TS in both the FB and PS group indicate that any variable would be able to indicate the balance ability provided the surface and leg dominance remain similar. The human bipedal stance is an unstable position because of the small base and heavier mass of head on the top. This is similar to an inverted 
pendulum that oscillates due to various internal and external factors (Schieppati, Tacchini, Nardone, Tarantola, \& Corna, 1999). Under conditions of quiet stance, the disturbance in balance is perturbed by respiratory and cardiac motion in addition to the development of fatigue in postural muscles. It is interesting to note that in single leg stance, one leg is lifted from the ground and remains hanging in the air without any support. The knee of the lifted leg remains protruded in an anterior direction which may cause a shift in the COM towards the front. In addition, it is possible that the muscles responsible for hip \& knee flexion get fatigued and thus the postural balance is disturbed.

\section{Effect of Leg Dominance}

It has been indicated that postural balance is destabilized when the COM and Centre of Pressure (COP) are at different locations (Shumway-Cook, \& Woollacott, 2007; Hong, Guo, Song, Nagurka, Sung, \& Yen, 2016). Also, the dominance of footedness was determined based of mobilizing action of kicking a football. There have been questions if a limb can be described as dominant in connection to the stability when the dominance is judged because of mobility factor (Gabbard, \& Hart, 2000). Absence of significant difference in median value, while comparing the effect of NDL and DL, is an indication that leg dominance issue might be a redundant factor in the evaluation of balance ability. It is further supported by the significant correlation between NDL and DL error values. Therefore, test with any leg, NDL or DL would possibly be sufficient for balance evaluation.

\section{Effect of Surface}

Surface hardness is a contributing factor in perturbations of human static balance (Simeonov, \& Hsiao, 2001). Caution was raised by Patel and colleagues (2008) in interpreting the balance test results using foam material as the surface since the softness of the foam may affect the result. Studies analyzing the postural sway in older persons have indicated the importance of visual information in stabilizing the body on foam surface (Tanaka, \& Uetake, 2005). It is thus natural to get a significant difference in the errors between FS and FOS that was evident in the present data. A few earlier studies have also exhibited less error score on the firm surface compared to foam surface (Patel, Fransson, Lush \& Gomez, 2008). The reason for non-statistically significant difference in errors between FS \& FOS for TS stance lies in the small number of errors in this stance with a large standard deviation that resulted in a high degree of overlapping in the data set as observed in figure 3. Statistically significant correlation of the errors on FS \& FOS in all conditions of leg dominance and stance contribute more to the idea that surface firmness may not be the criterion for balance evaluation in persons with visual impairments.

\section{Effect of Nature of Blindness}

Several studies have reported about the importance of vision in human posture control through the creation of reference system of the environment (Alotaibi et al., 2016; Dichgans, Mauritz, Allum, \& Brandt, 1976; Paulus, Straube, \& Brandt, 1984; Rutkowska et al., 2015). The data obtained in the present study have failed to show any difference between the PS and FB group possibly due to the specific experimental setup. The PS volunteers were blindfolded and thus they became similar in visual condition. It is also possible that the state of blindfoldedness is unnatural to the PS group to increase postural sway. In either case, it is indicative that in absence of vision even partially sighted persons would behave in a similar way to the full blind persons in respect to posture control. Such a phenomenon can happen if the posture control mechanism does not depend on visual inputs. 


\section{Conclusions}

The results of this study suggest that

- Blind persons have poor static balance skills and hence, impairment of visual functions is associated with increased postural instability.

- The double leg stance is not a necessity in the test set up. Elimination of one stance would reduce the testing duration and would enable more focus on the other two stances. Single leg stance is possibly the best indicator stance for balance ability of blind persons.

- It is possible that the long-term repetition of static balance, skills could improve the balancing ability and also maintain equilibrium. Further study is required to establish this particular issue.

\section{Perspectives}

Balance ability is an important issue in the field of mobility functions of persons with visual impairments. Loss of balance can lead to accidents in various adapted sports, especially in games like 5 a side football (Gamonales, et al, 2018). This study has highlighted a simple method of evaluation of static balance ability and has suggested further simplification by removing the double leg stance. With this simplified method, even an inclusive school-level implementation would be possible globally (Mikeska, et al 2016; Reina and Ruiz, 2016). Consequently, evaluation of the balance might help in orientation and mobility training to enhance the improvement in balance ability.

\footnotetext{
Author affiliations:

1 Ramakrishna Mission Vivekananda Educational and Research Institute; prasadtriloki27@gmail.com; asis.goswami@gmail.com

2 St. Xavier's College (Autonomous); subhankarghoshin@yahoo.co.in

* Correspondence: prasadtriloki27@gmail.com; Mobile: +919804216586
}

Author Contributions: Conceptualization: TP, AG; Data Collection: TP; Data Analysis: SG, AG, TP; WritingOriginal Draft Preparation: AG, SG; Writing-Review \& Editing: TP, AG, SG.

Funding: This research received no external funding

Acknowledgments: The authors are grateful to the volunteers, the Principal, and Staff of Louis Blind School, Uttarpara, West Bengal, for providing the space \& other facilities for this study and the Vice Chancellor of Ramakrishna Mission Vivekananda Educational and Research Institute (RKMVERI), Belur Math for his inspired guidance and all-around support.

Conflicts of Interest: The authors declare no conflict of interest.

\section{References}

Alotaibi, A. Z., Alghadir, A., Iqbal, Z. A., \& Anwer, S. (2016). Effect of absence of vision on posture. Journal of Physical Therapy Science, 28(4), 1374-1377. https://doi.org/10.1589/jpts.28.1374

Anand, V., Buckley, J. G., Scally, A., \& Elliott, D. B. (2003). Postural stability in the elderly during sensory perturbations and dual tasking: the influence of refractive blur. Investigative Ophthalmology \& Visual Science, 44(7), 2885-2891. https://doi.org/10.1167/iovs.02-1031

Aydoğ, E., Aydoğ, S. T., Cakci, A., \& Doral, M. N. (2006). Dynamic postural stability in blind athletes using the biodex stability system. International Journal of Sports Medicine, 27(5), 415-418. https://doi.org/10.1055/s-2005-865777

Bell, D. R., Guskiewicz, K. M., Clark, M. A., \& Padua, D. A. (2011). Systematic review of the balance error scoring system. Sports Health, 3(3), 287-295. https://doi.org/10.1177/1941738111403122

Broglio, S. P., Zhu, W., Sopiarz, K., \& Park, Y. (2009). Generalizability theory analysis of balance error scoring system reliability in healthy young adults. Journal of Athletic Training, 44(5), 497-502. https://doi.org/10.4085/1062-6050-44.5.497

Cohen, L. G., Celnik, P., Pascual-Leone, A., Corwell, B., Falz, L., Dambrosia, J., ... Hallett, M. (1997). Functional relevance of cross-modal plasticity in blind humans. Nature, 389(6647), 180-183. https://doi.org/10.1038/38278 
Collins, M. W., Grindel, S. H., Lovell, M. R., Dede, D. E., Moser, D. J., Phalin, B. R., ... McKeag, D. B. (1999). Relationship between concussion and neuropsychological performance in college football players. JAMA, 282(10), 964-970. https://doi.org/10.1001/jama.282.10.964

Dichgans, J., Mauritz K. H., Allum J. H., \& Brandt T. (1976). Postural sway in normals and atactic patients: analysis of the stabilising and destabilizing effects of vision. Agressologie. 17(C Spec No):15-24. (PMID: 1008137)

Docherty, C. L., Valovich McLeod, T. C., \& Shultz, S. J. (2006). Postural control deficits in participants with functional ankle instability as measured by the balance error scoring system. Clinical Journal of Sport Medicine, 16(3), 203-208. https://doi.org/10.1097/00042752-200605000-00003

Fregly, A.R. (1975) Vestibular ataxia and its measurement in Man. In: H. H. Kornhuber (Ed) Vestibular System Part 2: Psychophysics, Applied Aspects and General Interpretations (pp. 321-360). Berlin, Germany : Springer https://doi.org/10.1007/978-3-642-65920-1

Friedrich, M., Grein, H. J., Wicher, C., Schuetze, J., Mueller, A., Lauenroth, A., ... Schwesig, R. (2008). Influence of pathologic and simulated visual dysfunctions on the postural system. Experimental Brain Research, 186(2), 305-314. https://doi.org/10.1007/s00221-007-1233-4

Gabbard C., \& Hart S. (2000) Examining the notion of foot dominance. In: M. K. Mandal, B. Bulman-Fleming, \& G. Tiwari. (Eds) Side bias: A neuropsychological perspective (pp. 249-265). Dordrecht, Germany: Springer. https://doi.org/10.1007/o-306-468840_10

Gamonales, M.J., Munoz-Jimenez, J., Leon-Guzman, K., \& Ibanez, J.S. (2018) 5-a-side football for individuals with visual impairments: A review of the literature. European Journal of Adapted Physical Activity, 11(1), 4. https://doi.org/10.5507/euj.2018.004

Guskiewicz K. M. (2001). Postural stability assessment following concussion: one piece of the puzzle. Clinical Journal of Sport Medicine, 11(3), 182-189. https://doi.org/10.1097/00042752-200107000-00009

Guskiewicz, K. M., \& Perrin, D. H. (1996). Research and clinical applications of assessing balance. Journal of Sport Rehabilitation, 5(1), 45-63. https://doi.org/10.1123/jsr.5.1.45

Hassan, A.A. (1989). A comparison of static and dynamic balance among blind, deaf and non-handicapped primary school age children in the state of Bahrain. Bahrain Medical Bulletin, 11(2), 68-76. https://www.bahrainmedicalbulletin.com/issue_aug1989.html

Hile, E. S., Brach, J. S., Perera, S., Wert, D. M., VanSwearingen, J. M., \& Studenski, S. A. (2012). Interpreting the need for initial support to perform tandem stance tests of balance. Physical Therapy, 92(10), 1316-1328. https://doi.org/10.2522/ptj.20110283

Hong, C. Y., Guo, L. Y., Song, R., Nagurka, M. L., Sung, J. L., \& Yen, C. W. (2016). Assessing postural stability via the correlation patterns of vertical ground reaction force components. Biomedical Engineering Online, 15(1), 90. https://doi.org/10.1186/s12938-016-0212-Z

Horak, F. B., Diener, H. C., \& Nashner, L. M. (1989). Influence of central set on human postural responses. Journal of Neurophysiology, 62(4), 841-853. https://doi.org/10.1152/jn.1989.62.4.841

Horvat, M., Ray, C., Ramsey, V. K., Miszko, T., Keeney, R., \& Blasch, B. B. (2003). Compensatory analysis and strategies for balance in individuals with visual impairments. Journal of Visual Impairment and Blindness, 97(11), 695-703. https://doi.org/10.1177/0145482X0309701103

International Classification of Diseases (ICD-10, 2016) https://icd.who.int/browse10/2016/en\#h53-h54

Jansen, E. C., Larsen, R. E., \& Olesen, M. B. (1982). Quantitative Romberg's test. Measurement and computer calculation of postural stability. Acta Neurologica Scandinavica, 66(1), 93-99. https://doi.org/10.1111/j.1600-0404.1982.tbo3132.x

Jonsson, E., Seiger, A., \& Hirschfeld, H. (2005). Postural steadiness and weight distribution during tandem stance in healthy young and elderly adults. Clinical Biomechanics, 2O(2), 202-208. https://doi.org/10.1016/j.clinbiomech.2004.09.008 
McCrea, M., Kelly, J. P., Kluge, J., Ackley, B., \& Randolph, C. (1997). Standardized assessment of concussion in football players. Neurology, 48(3), 586-588. https://doi.org/10.1212/wnl.48.3.586

Mikeska, D., Jesina, O., Kudlacek, M., Janecka, Z., \& Kalman, M. (2016) Determinants of physical activity and lifestyle of Czech 11-15 years old students with visual impairments. European Journal of Adapted Physical Activity, 9(2):30-37. https://doi.org/10.5507/euj.2016.008

Nashner, L. M., Black, F. O., \& Wall, C., 3rd (1982). Adaptation to altered support and visual conditions during stance: patients with vestibular deficits. The Journal of Neuroscience, 2(5), 536-544. https://doi.org/10.1523/JNEUROSCI.02-0500536.1982

Patel, M., Fransson, P. A., Lush, D., \& Gomez, S. (2008). The effect of foam surface properties on postural stability assessment while standing. Gait \& Posture, 28(4), 649-656. https://doi.org/10.1016/j.gaitpost.2008.04.018

Paulus, W. M., Straube, A., \& Brandt, T. (1984). Visual stabilization of posture. Physiological stimulus characteristics and clinical aspects. Brain: A Journal of Neurology, 107(4), 1143-1163. https://doi.org/10.1093/brain/107.4.1143

Razali, N. M., \& Wah, Y. B. (2011). Power comparisons of Shapiro-Wilk, KolmogorovSmirnov, Lilliefors and Anderson-Darling tests. Journal of Statistical Modeling and Analytics, 2(1), 21-33.

Reina, R., \& Ruiz, A.J. (2016) Full inclusion of a student with visual impairment over the full physical activity and sport sciences degree: A case study. European Journal of Adapted Physical Activity, 9(1):40-52. https://doi.org/10.5507/euj.2016.004

Riemann, B. L., Guskiewicz, K. M., \& Shields, E. W. (1999). Relationship between clinical and forceplate measures of postural stability, Journal of Sport Rehabilitation, 8(2), 7182. https://doi.org/10.1123/jsr.8.2.71

Rutkowska, I., Bednarczuk, G., Molik, B., Morgulec-Adamowicz, N., Marszałek, J., Kaźmierska-Kowalewska, K., \& Koc, K. (2015). Balance functional assessment in people with visual impairment. Journal of Human Kinetics, 48, 99-109. https://doi.org/10.1515/hukin-2015-0096

Schieppati, M., Tacchini, E., Nardone, A., Tarantola, J., \& Corna, S. (1999). Subjective perception of body sway. Journal of Neurology, Neurosurgery, and Psychiatry, 66(3), 313-322. https://doi.org/10.1136/jnnp.66.3.313

Shumway-Cook, A., \& Horak, F. B. (1986). Assessing the influence of sensory interaction of balance. Suggestion from the field. Physical Therapy, 66(10), 1548-1550. https://doi.org/10.1093/ptj/66.10.1548

Shumway-Cook, A., \& Woollacott, M. H. (2007). Motor control: translating research into clinical practice (pp.161-170). Baltimore, USA: Lippincott Williams \& Wilkins.

Shupert, C. L., Horak, F., \& Black, F. O. (1992). Effect of peripheral vestibular disorders on head-trunk coordination during postural sway in humans. In: A. Berthoz, W. Graf, \& P. P. Vidal, (eds) The head-neck sensory motor system (pp.607-610). Oxford: Oxford University Press. https://doi.org/10.1093/acprof:oso/9780195068207.003.0099

Simeonov, P., \& Hsiao, H. (2001). Height, surface firmness, and visual reference effects on balance control. Injury Prevention, $7($ Suppl 1), i50-i53.

https://doi.org/10.1136/ip.7.suppl_1.i5o

Sugano, H., \& Takeya, T. (1970). Measurement of body movement and its clinical application. The Japanese Journal of Physiology, 20(3), 296-308. https://doi.org/10.2170/jjphysiol.20.296

Stewart, A., Marfell-Jones, M., Olds, T., \& Ridder, D. H. (2011). International standards for anthropometric assessment. Lower Hutt, New Zealand: International Society for the Advancement of Kinanthropometry.

Tanaka, H., \& Uetake, T. (2005). Characteristics of postural sway in older adults standing on a soft surface. Journal of Human Ergology, 34(1-2), 35-40. https://doi.org/10.11183/jhe1972.34.35

Théoret, H., Merabet, L., \& Pascual-Leone, A. (2004). Behavioral and neuroplastic changes in the blind: evidence for functionally relevant cross-modal interactions. Journal of Physiology, 98(1-3), 221-233. https://doi.org/10.1016/j.jphysparis.2004.03.009 
Winter, D. A. (2009). Biomechanics and Motor Control of Human Movement. Chichester: John Wiley \& Sons, Inc.

(C) 2020 by the authors. Submitted for possible open access publication under the terms and conditions of the Creative Commons Attribution (CC BY) license (http://creativecommons.org/licenses/by/4.o/). 